$\underline{\text { Professor C C de Silva Oration } 2008}$

\title{
Some facets of laterality in Sri Lankan children
}

\section{B J C Perera}

Sri Lanka Journal of Child Health, 2009; 38: 4-20

(Key words: Laterality, Sri Lankan children)

\section{Foreword}

Ladies and Gentlemen, it was seventeen years ago on the $22^{\text {nd }}$ of February 1991 that I was fortunate enough to be afforded the singular privilege of presenting my very first Professor C C de Silva Memorial Oration. It was on "Changing frontiers in childhood asthma". Some of you who were present on that day may perhaps remember how I recounted the progression of my association with Professor C C de Silva. With apologies to those who have heard it before, I wish to start this presentation on a similar personal note.

As a third year medical student in the late sixties, while listening to Professor C C de Silva asking some questions during a lecture on an esoteric subject by a renowned researcher, I thought he was a spent old force. He had just retired and I thought to myself that I would be spared any exposure to this old busybody. In fact, he had asked some questions which were so very relevant to our motherland. The questions were of course well over my own stupid head and hence the gravely mistaken opinion of a raw medical student.

The second time I came across him was the occasion during my internship when I had the audacity to write my very first scientific paper. I was sent to him by the Editor for assessment of my script. I thought that I had written an absolute masterpiece and this was just a formality. He sat me down and simply just took the paper apart. He got me to type it repeatedly and bring it back to him only for him to find some fault each and every time. Those were the good old days before computers and word processors. Each word had to be carefully typed on a manual typewriter. I was a novice at typing too and had to look for the letters on the keyboard of the typewriter each time I wanted to type anything. I spent hours typing this miserable script. Nothing escaped his razor sharp mind. I was beginning to change my original impression of him as a spent old force. He got me to type it seven times and finally I begged for mercy

\footnotetext{
${ }^{1}$ Consultant Paediatrician, Colombo
}

from the Editor and it was published. That episode was most definitely a baptism by fire. When I look back at that very first paper, I feel justifiably proud of what I had written but it was of course almost totally rewritten by Professor C C.

From that time onwards and over the years Professor C C de Silva made it a point to attend many of my presentations. I have often wondered why but I cannot think of a plausible reason for it. Perhaps, he could look into the future and see something I could not see. Each and every time he also had several constructive suggestions on some aspects of the presentation. By this time I had completely changed my original opinion of him and his comments were most welcome. He became my mentor in scientific writing and academic presentations. Over the years, I have had the good fortune to make numerous presentations and publish original scientific articles. The basics of scientific presentations and writing that I learned at the feet of the master were absolutely invaluable in all these endeavours. I had developed an admiration, respect and affection for the man that was second only to those reserved for my own parents.

Professor C C de Silva was a colossus among the medical giants of his era. He was undoubtedly the father of modern scientific paediatrics in this country. His achievements are a legion and are well known. It is not my intention to chronicle them. However, I believe that being selected to present this oration for the third time in memory of one of my most respected teachers is definitely the zenith of my career. A few days before I presented the first one in 1991, I took the first few pages of the oration which were written on the same lines as this one, to his gracious wife and asked her to read and approve it. I was quite worried as the introduction was just a little bit uncomplimentary as it is in this one. After all, I had called him a spent old force initially. I told her, "Madam, if you have any reservations whatsoever about what I have written, please tell me and I will change the script even if I have to do it more than seven times if necessary". She carefully read through 
the first couple of pages, laughed out aloud and said "Please don't change a word of it. I love it as it is". Now that she is gone as well, today, both of them must be looking down together from their heavenly abode, chuckling to themselves and saying "There he goes, the boyo is at it, again".

Madam President, the following narration is my personal tribute to a man who was definitely like no other in the academic paediatric scenario of Sri Lanka.

\section{Preamble}

The human body ostensibly consists of the spectacle of a perfect midline fusion of two mirror-image halves. It has perfect duplication of the leg, arm, ear, eye etc., on each side of the body. Yet, in many day to day activities, the humans use just one side of the body or just one limb of the body. Thus, in reaching, pointing, eating, writing, combing, brushing, painting, using a hammer, throwing, jumping, kicking and in some sports, just to name only a few, one is called upon to use predominantly one side or one component of a given side of the body. In addition, many persons have a dominant eye and a dominant ear. These in combination have led to the notions of handedness, footedness, eyedness and facedness. The fundamental basis of these perceptions is the concept of laterality ${ }^{1}$. The best known and the most studied component of laterality is handedness which signifies adeptness of the use of a hand for most activities. The great majority have greater skills with the use of the right hand and are designated right handed. The impressions of footedness and eyedness are perhaps less familiar but they stem from the same principle of laterality as handedness. A celebrated neurologist of Sri Lanka, Dr. George Ratnavale, once postulated that if one could do anything better with the left hand than with the right hand, then, that individual is a born left hander.

The human cerebral hemispheres show well defined specialisation and partiality towards certain specified functions. Thus, the left hemisphere is especially involved with language functions while the right one is concerned with visual-spatial activities. Just as they show specialisation for these well defined activities, they also show preferences and asymmetries for other bodily functions. The hand preference in handedness, foot preference in footedness and eye preference in eyedness are the manifestations of dominance of the contralateral cerebral hemisphere in these activities. The littleknown idea of facedness refers to the strength with which information is conveyed by the right or left side of the face. It has been suggested that verbal information shows a right-face bias while emotional expressions are more strongly shown on the left side of the face ${ }^{2}$. Laterality, in simpler terms is the behavioural manifestations of cerebral dominance in which there is preferential use and superior functioning of either the left or the right side ${ }^{3}$.

For a long time it was believed that the ability to be left or right handed was uniquely human. This notion is likely to have been inculcated by its linkage to our distinct right and left brain tendencies to handle different aspects of human intelligence. The right side is thought of as being more "creative" and the left side more "logical."

The first conclusive break with this idea came with chicks, which, it turns out, tend to use the left side of their brains linked to the right eye to look for food and the opposite side of the brain and opposite eye to watch for predators ${ }^{4}$. Actual handedness, where one asks if there is a preference between the use of one hand or paw, has also been seen in non human animals. For example, marmosets which are small monkeys with bushy tails, can be left or right-handed with the distinction being based on which hand is used more.

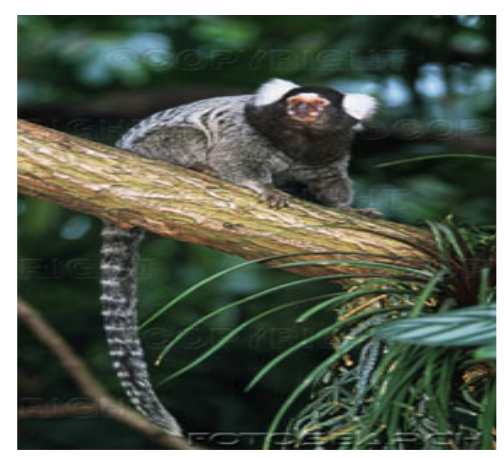

Interestingly, about half of the marmosets in the wild are right-handed and half are left-handed. So there's no obvious survival preference attached to handedness in this case. The left-handed ones tend to have personalities that are more nervous and shy while the right-handed ones are more outgoing. This echoes the data from chicks, where right-handed, that is left-brained animals, seem to be more likely to go around looking for things like food more openly and with curiosity while others tend to be more introverted and better at watching out for threats. One of the most interesting recent examples of handedness in non-humans is found in some snaileating snakes in Southeast Asia. The snails can have spirals that come out from the centre in a clockwise 
fashion, that is right-handed or in a counterclockwise fashion that is left-handed. The snakes have more teeth on the right side of their mouths than on the left, helping them extract and eat right-handed snails more efficiently. Consequently, where these snakes are found, there is a preponderance of left-handed snails presumably because the snakes prefer to eat the right handed snails. Scientists have recently found that like humans, walruses express "handedness", the preference of one side of the body over the other when performing certain tasks.

The vast majority of humans are right handed and many are right-sided in general. That is, they prefer to use their right eye, right foot, and right ear if forced to make a choice between the two sides. The reasons for this are not fully understood. The left cerebral hemisphere controls the language functions of man and language is the symbolic expression of thought. These processes of thinking and language are the ones that clearly distinguish the human species from its closest evolutionary ancestors ${ }^{5}$. Thus it is thought that as it controls such a unique function, the left cerebral hemisphere is dominant over the right in the majority of people and as such they manifest right laterality. Yet for all this, and curiously enough, it has been established that even in the majority of left handers, the language functions are controlled by the left hemisphere and not by the right $^{6}$.

Globally, around 8 to 15 percent of people are lefthanded $^{7}$. There are many theories as to why some individuals are left-handed ${ }^{8}$. Undoubtedly, there are points for and against each of these theories. The most accepted one is the division of labour in the brain hemispheres. It postulates that since both speaking and handiwork require fine motor skills, it would be more efficient for both to be localised to one hemisphere rather than having them divided. This tends to explain right-handedness but fails to clarify why the majority of lefties have the language functions on the left hemisphere. Another postulates that there is strong evidence that prenatal testosterone levels play a part in brain organisation and high levels make one left-handed. This is corroborated by the fact that left-handedness is commoner in males than in females. The incidence of left handedness is around $10 \%$ in men while it is around $8 \%$ in women. Another theory states that being left-handed is a manifestation of brain damage during the birth process. A genetic basis for left-handedness has also been mooted as it tends to run in families. Righthanded dominance in society is also thought to be the result of parental pressure from right handed parents. Even excessive pre-natal ultrasound scanning has been implicated as a factor for making an individual left-handed ${ }^{9}$. However, the exact reason why righthandedness is more common in humans and other animals than left-handedness is yet to be explained in a plausible manner.

Since the times of Darwin, it has been known that left-handedness in humans runs in families. However, it is rather a complicated system of genetic inheritance that leads to it running in families ${ }^{10}$. It appears that one gene, labelled 'D', causes people to have the textbook 'normal' asymmetries of the brain leading to features such as being right-handed and probably also having the language centre in the left half of the brain and having hair that whorls clockwise on the head. An alternative version of the gene, labelled ' $C$ ', leads to failure to determine which side of the brain each specialised area will develop in and so each such area has a 50 percent chance of developing in either the left or right side.

This system means that people who have two copies of the 'D' gene will be right-handed as well as having hair that whorls clockwise and a 'normal' brain configuration. People who carry two copies of the ' $\mathrm{C}$ ' gene will have a 50 percent chance of being lefthanded and are also thought to have a 50 percent chance of every other asymmetry of the brain being in the opposite hemisphere from 'normal'. This perhaps explains why identical twins sometimes have different hand preferences.

People who have one ' $\mathrm{C}$ ' and one 'D' gene have a 25 percent chance of being left-handed and probably also a 25 percent chance of each specialised region of the brain being in the opposite half from 'normal'. Thus, if one is left-handed then he or she must have at least one ' $\mathrm{C}$ ' gene. But, some right-handers will also have the ' $\mathrm{C}$ ' gene. Another external clue seems to be hair whorling counter-clockwise on the head, which is now also thought to indicate the presence of the ' $\mathrm{C}$ ' gene.

If it is true that other areas of the brain are also affected by the ' $\mathrm{C}$ ' gene, it might explain why lefthanded people are over-represented among people with speech difficulties, schizophrenia and dyslexia and some people with a ' $\mathrm{C}$ ' gene may have a brain make-up that makes them particularly talented compared with 'normal' 'DD' people.

In 2007 Clyde Francks et al from Oxford, UK, reported the discovery of a specific component of genetic material in cells known as Leucine-rich repeat transmembrane neuronal 1 gene or LRRTM1 
gene which is able to increase the odds of being left handed $^{11}$. LRRTM1 is an imprinted gene in humans that shows a variable pattern of maternal downregulation and is expressed during the development of specific forebrain structures. Thus it could influence neuronal differentiation and connectivity. This is an important discovery of a potential genetic influence on human handedness and the first putative genetic effect on variability in human brain asymmetry.

The fine distinctions between left and right handers play important roles in areas of sensation and perception, engineering psychology, neuropsychology, reaction times, human-machine interactions and even ergonomic designs ${ }^{2}$.

\section{Socio-cultural and historical aspects of laterality}

Human cultures are predominantly right-handed and as such, right-sided trend may have been socially as well as biologically enforced. In addition, throughout history, being left-handed had profound negative connotations. This is apparent even from a survey of languages. The English word "left" is derived from the Anglo-Saxon word lyft which means weak or useless. The English word "right" was plagiarised from the Anglo-Saxon word riht meaning "straight" or "correct". The French word for left, gauche, is also used to mean "awkward" or "tactless". The Latin word sinistra from which the English word "sinister" was derived, simply means left.

Inuit, the native inhabitants of the Arctic region, firmly believed that every left-hander was a sorcerer. A Japanese man could divorce his wife if he discovered that she was left-handed. Chinese in general and Taiwanese in particular strongly encouraged the left-handers to at least switch over to right handed writing as it is extremely difficult to write legible Chinese characters with the left hand. The Latin alphabet too is easier handled by righties than lefties. However, the so called right-to-left writing languages like Arabic and Hebrew show up an obvious advantage for the left-handers ${ }^{8}$.

Yet for all this, the more active right cerebral hemisphere in left-handers is thought to be associated with some traits that border on the characteristics of genius $^{8}$. In some individuals, it is known to correlate strongly with exceptional artistic and visual skills ${ }^{8}$. This concept is reinforced by many chronicles of world history which are replete with famous lefthanders.
Among the royalty, nobility and recognised leaders of populations, there have been several outstanding left-handers. Alexander the Great, Tiberius, Julius Caesar, Napoleon Bonaparte, Joan of Arc and Adolf Hitler were left-handed. In the present Royal Family of Great Britain, Queen Elizabeth II, Prince Charles and Prince William are left-handers. Among the leaders of countries, Gerald Ford, Bill Clinton, George W Bush and Margaret Thatcher were lefties. Among the artists, well known personalities like Michaelangelo and Leonardo da Vinci were lefthanders. Several famous authors like Samuel Beckett, Charles Dickens, Peter Benchley, Leo Tolstoy and H G Wells were left-handed. Some celebrated musicians and composers like Johann Bach, Ringo Starr, Paul McCartney, Glen Campbell, Natalie Cole and Art Garfunkel were left-handed. Among actors and entertainers, Peter O-Toole, Woody Allen, Jennifer Coolidge, Michael Crawford, Peter Fonda, Paul Michael Glaser, Goldie Hawn, Benny Hill, Robert Redford, Rod Steiger and Oprah Winfrey are left-handers. Some of the greatest sportspersons were left-handers. In cricket, Wasim Akram, Allan Border, John Edrich, Stephen Fleming, Saurav Ganguly, Adam Gilchrist, Sir Richard Hadlee, Mathew Hayden, David Gower, Brian Lara and Sir Garfield Sobers, just to name a few, were left-handers. Even in our current national cricket team, Sanath Jayasuriya, Kumar Sangakkara and Chaminda Vas are celebrated lefties. It is interesting that Sachin Tendulkar, arguably the best batsman ever, bats and bowls right handed but writes left handed. It is speculated that he is a born left-hander who had been converted to a right-hander.

Even among well known criminals there are some prominent lefties. Some of them are names like John Dillinger, the well known bank robber, Albert Henry De Salvo, better known as the Boston Strangler and Jack the Ripper. In today's context, Osama bin Laden and the less well known Abu Musab al-Zarqawi who ran a militant training camp in Afghanistan alongside Osama bin Laden and was the most wanted man in Jordan and Iraq, are left-handers.

\section{The literature on laterality and justification for the current presentation}

There is a considerable amount of work done and a plethora of information readily available in the international medical literature on laterality. In some of them, much interest has been shown towards cerebral dominance and its evaluation and association with many other aspects. Internationally, the work done extends from perceived association of lefthandedness with immune disorders, migraine and 
learning disorders ${ }^{12}$, reduced longevity of lefties ${ }^{13}$ to handedness related differences in ability ${ }^{14}$. Allergic diseases are also thought to be commoner among left handers ${ }^{15}$ and even autoimmune thyroiditis has been postulated to be more frequent in the left-handed ${ }^{16}$.

However, there is a considerable vacuum of information regarding laterality from the Asian region and a virtual absence of any work done on it in Sri Lanka, particularly among children. Up to a few years ago, when we started our work on laterality, even the incidence of left-handedness had not been evaluated in Sri Lankans. This presentation is the first documentation of some varied aspects of laterality in Sri Lankan children. It consists of three different studies done by us in Sri Lanka. The first looks at the incidence of laterality in school children. The second examines handedness in elite tennis playing children in Sri Lanka while the third assesses the vagaries of injuries and laterality in children who take part in different sports at a competitive level. The three studies looked at a total of 3875 children and adolescents.

\section{Laterality in Sri Lankan children}

The work done by us on laterality started with a curious incident. Some time in the latter half of 1997 , a group of medical students had just completed their clinical appointment with us. This was a particularly good and keen group, perhaps a rarity in this day and age. Their surnames started with the letter $M$ and we called them "The M Group". On the last day of the appointment they brought some cakes and sweetmeats and tried to felicitate us for teaching them. During the ensuing discussion over tea, I casually inquired whether any of them were interested in research. To my utter surprise every single one of them put the hand up. I thought that this was just a flash in the pan and told them to come and meet me again after a couple of weeks. I did not really expect them to come back.

Lo and behold, two weeks later seven of them turned up. I first gave them the option of working on some aspect of paediatrics on which they had some interest. They did not have any particular subject in mind. Then I suggested to them that it would be a good idea to do some work on laterality. They readily agreed. We proceeded to do an extensive literature search and plan the project. The main objectives of the study were firstly to ascertain the prevalence of handedness and secondly to assess the usefulness of certain clinical observations in determining handedness.
The clinical observations that were to be noted were as follows:

$>$ Hand clasping - Assessment of which thumb is on top during voluntary clasping of hands.

$>$ Arm folding - Scrutiny of which hand is on top in voluntary folding of arms.

$>$ Leg crossing - Determination of which leg is on top in voluntary leg crossing.

$>$ Needle threading - Evaluation of which hand was used to hold the thread.
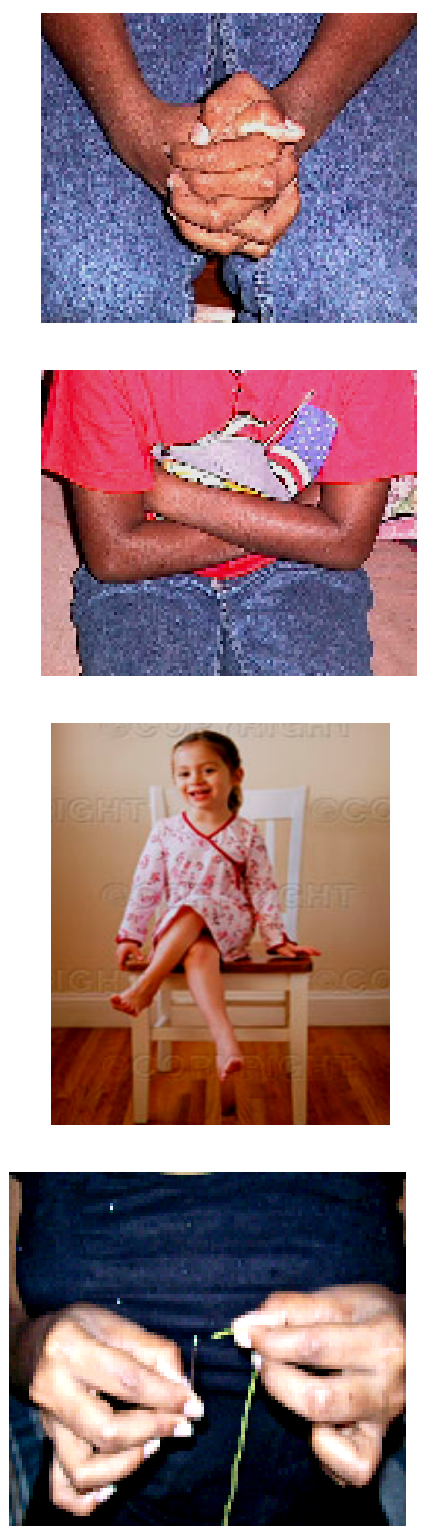

It was designed as a prospective observational double-blind study in 14 schools in Colombo. We got the required consent and authority for the study from the principals of the schools and commenced 
collecting data in February 1998. We collected the data from all Year 7 children in the age group of 11 to 13 years. The children were told that this was a medical research study but the exact purpose which was to determine handedness was not divulged to them. It helped to maintain the situation whereby the subjects were unaware of or "blind" to the objective of the study. This step was also taken to prevent some mischievous children, purposefully providing misleading information as such behaviour patterns are known to occur in this age group.

The research team was divided into two groups. The first group collected data on the race, age, sex and the hand used in eating, writing and throwing a ball. The second group, which was "blind" to the details obtained by the first group, assessed details of hand clasping, arm folding and needle threading. At the end of each day, the results were merged and entered into a purpose-designed computer database in EPI INFO Version 6. The results were analysed using the inherent capabilities of the same computer programme. Stringent steps were taken to ensure reliability of the data and to avoid the occurrence of other confounding factors as far as possible.

The total number of children assessed was 2860 . There were 1564 males and 1296 females. The vast majority $(98 \%)$ were in the 11 to 12 year age group. Ethnicity of the sample is represented in Table 1.

Table 1

Ethnicity of the entire cohort.

\begin{tabular}{|l|c|}
\hline Sinhalese & $87.1 \%$ \\
\hline Muslims & $10.3 \%$ \\
\hline Tamils & $2.3 \%$ \\
\hline Others & $0.3 \%$ \\
\hline
\end{tabular}

The results of the assessment of the hand used for eating, writing and throwing a ball are given below in Table 2 .

Table 2

Details of the hand used for different activities

\begin{tabular}{|l|l|c|}
\hline & $\begin{array}{c}\text { Left handed } \\
(\mathbf{\%})\end{array}$ & $\begin{array}{c}\text { Non-left } \\
\text { handed (\%) }\end{array}$ \\
\hline Eating & $68(2.4 \%)$ & $2792(97.6 \%)$ \\
\hline Writing & $270(9.4 \%)$ & $2590(90.6 \%)$ \\
\hline Throwing a ball & $251(8.8 \%)$ & $2609(91.2 \%)$ \\
\hline
\end{tabular}

We then looked at possible combinations of these to see their correlation. Results are depicted in Table 3.

Table 3

Correlation of combinations of the hand used for different activities

\begin{tabular}{|l|c|}
\hline & $\begin{array}{c}\text { Correlation Coefficient } \\
\text { (r) }\end{array}$ \\
\hline $\begin{array}{l}\text { Eating and writing } \\
\text { with the left hand }\end{array}$ & 0.4 \\
\hline $\begin{array}{l}\text { Eating and throwing } \\
\text { with the left hand }\end{array}$ & 0.4 \\
\hline $\begin{array}{l}\text { Writing and } \\
\text { throwing with the } \\
\text { left hand }\end{array}$ & $\mathbf{0 . 8}$ \\
\hline
\end{tabular}

The use of the left hand for a combination of writing and throwing a ball showed the best correlation to denote left handedness. Using this combination we deduced that $211(7.4 \%)$ of the total number of 2860 were left handed. Of this number of left handers, as determined by this combination, $58 \%$ were males and $42 \%$ were females.

We also proceeded to look at the usefulness of the clinical observations or physical signs of hand clasping, arm folding, leg crossing and needle threading as indicators of laterality. The results are given in Table 4.

Table 4

Handedness and clinical observations

\begin{tabular}{|l|c|c|}
\hline & $\begin{array}{c}\text { Left handers } \\
(\mathbf{\%})\end{array}$ & $\begin{array}{c}\text { Non-left } \\
\text { handers }(\mathbf{\%})\end{array}$ \\
\hline Hand clasping & 48.6 & 51.4 \\
\hline Arm folding & 55.9 & 44.1 \\
\hline Leg crossing & 13.7 & 86.3 \\
\hline Needle threading & 16 & 84 \\
\hline
\end{tabular}

It appeared that hand clasping and arm folding were not useful signs when used individually as the percentages were not tenable and totally at variance with the world literature. Leg crossing and needle threading showed some promise but the percentages were much higher than the $7.4 \%$ left handers as determined by writing and throwing with the left hand. However, an interesting sub-analysis using different combinations of these permutations is given below in Table 5 . 
Table 5

Left handedness and different permutations of the hand used for certain activities

\begin{tabular}{|l|c|c|}
\hline \multicolumn{1}{|c|}{$\begin{array}{c}\text { Left handed } \\
\text { number } \\
\quad+\end{array}$} & $\begin{array}{c}\text { Left handed } \\
\text { percentage }\end{array}$ \\
\hline $\begin{array}{l}\text { Writing and throwing with the left hand } \\
\text { Those who either wrote or threw with the right hand but had all } 4 \\
\text { physical signs of left handedness }\end{array}$ & $227 / 2860$ \\
\hline $\begin{array}{l}\text { Writing and throwing with the left hand } \\
\quad+\end{array}$ & $\mathbf{7 . 9} \%$ \\
$\begin{array}{l}\text { Those who either wrote or threw with the right hand but had } 3 \text { of } \\
\text { the } 4 \text { physical signs of left handedness }\end{array}$ & $286 / 2860$ \\
\hline
\end{tabular}

Thus it was concluded that the maximum possible percentage of left handers in this study was $10 \%$. This figure compares favourably with the global range of 8-15 per cent of the population being left handed $^{6}$. Most studies have used a four item selfreport inventory using the hand employed to write, hold a toothbrush, erase and to throw a ball. This is the first time in the medical literature that the combination of the hand used for writing and throwing together with the clinical observations / physical signs of hand clasping, arm folding, leg crossing and the hand used to thread a needle were used to determine handedness.

The original paper on this study was presented at the Annual Scientific Congress of The Sri Lanka College of Paediatricians in $1998^{17}$. On my insistence, the paper was presented in a very interesting and competent manner by one of the lady medical students of the research team who is now a practising doctor. The jewel of the crown was that the paper was adjudged the best paper of the Congress.

\section{Some intricacies of handedness in young tennis players}

My involvement in tennis as a player, coach, commentator and a sports physician is well known. In fact, perhaps rather unkindly, my colleagues have often referred to me in terms of a tennis player masquerading as a paediatrician. It would perhaps come as no surprise that my next endeavour was to look at laterality in elite tennis playing children and adolescents in the National Tennis Centre, Green Path, Colombo 7.

In 1999 we assessed handedness among the cream of the crop of tennis playing children and adolescents in Colombo and compared the left and right handers with reference to their playing ability using the national ranking system of the Sri Lanka Tennis Association. All tennis playing children who were under training and were between the ages of 8 and 18 years were enrolled. An interviewer administered questionnaire elicited details of the hand used to write, eat, throw a ball, hold a toothbrush and the racquet-hand used to serve the ball in tennis. A total of 193 players were assessed. Male to female ratio was 112: 81 . The average age was 13 years and 10 months. Left handedness was determined using a combination of the hand used to write, throw a ball, hold a toothbrush and the racquet-hand utilised in serving the ball while playing tennis.

Using these criteria, it was found that $16.5 \%$ of the elite tennis players in Colombo were left handed. The variability in the different age groups was in the range of 13.6 to 19.2 percent. There was no significant difference in the National Rankings of the left handers when compared to the right handers.

This work was presented at the Annual Scientific Congress of The Sri Lanka College of Paediatricians in August $2000^{18}$. There was a significantly higher proportion of left handers among this group of elite tennis players but they did not seem to be superior in their playing abilities when compared to the right handers.

It has been claimed that being left handed provides a certain advantage to many sportspersons in general and to tennis players in particular. The presumption in tennis is that about $90 \%$ of the time left handers have to play against right handers and the right handers get to play against left handers only around $10 \%$ of the time. Generally, the Achilles heel of any tennis player is the back-hand stroke. The stronger shot is the fore-hand drive. Most fore-hand drives of 
left handers are directed towards the right handers back-hand. But the right handers come across this problem against the lefties only $10 \%$ of the time. All right handers fore-hand drives go to the left handers back-hand side and the lefties come across this phenomenon $90 \%$ of the time. As a result the left handers back-hand strokes get stronger as they have to cope with this problem $90 \%$ of the time. Besides, the left handers serve, coming as it seems from the wrong side, is a formidable weapon against the right handers. Many famous tennis players in the world were and are left handed. Among the men are such champions as Rod Laver, Neale Fraser, Tony Roche, Jimmy Connors, John McEnroe, Guillarmo Villas and Raphael Nadal. Among the women are the famous names such as Martina Navaratilova, Monica Seles and Renee Richards. Arguably the one tennis player who has been acclaimed as the best ever, the one who won three Grand Slams on three separate occasions, Rod Laver of Australia was left handed. However, the sport in which left handers show significant dominance is fencing. There are more left handed champions in fencing than in any other sport.

\section{Handedness and sports injuries}

It is also a fascinating observation that left handedness has been associated with a significantly higher incidence of injuries in many activities. The general incidence of a number of injuries has been associated with left handedness ${ }^{19}$. Left laterality has been linked to head injuries ${ }^{20}$, upper limb injuries ${ }^{21}$ and even fractures ${ }^{22}$. It has been associated as a risk factor for all unintentional injuries in adolescents in general $^{23}$ and adolescent girls in particular ${ }^{24}$. Left handedness has been broadly linked to sports injuries $^{25}$, especially in adolescents ${ }^{26}$. Injuries are almost a part and parcel of sports participation and higher the degree of participation the more important would be the incidence and causation of injuries. However, there were no publications on the relationship of laterality to the side of the injury in the world literature.

It was also noted that there was a marked dearth of studies in all these aspects from the Asian region. I thought that it would be appropriate to try and look at this aspect in a research setting. In the middle of the year 2006 we managed to get a research team organised to look at the relationship, if any, between handedness, footedness and sports injuries. It was our considered opinion that it would be best to try and assess the injuries in children taking part in competitive sport. The study was carried out in ten Colombo schools and we looked at the sports injuries against the backdrop of handedness or footedness in children aged 10 to 18 years who were in the agestratified representative sports teams of the schools. The design was that of a prospective, double-blind, observational study. Permission for the study was obtained from the pincipals of the schools and consent was secured from the parents of the children. All children and adolescents playing in the school teams in cricket, rugby, soccer, basketball, volleyball, hockey, netball, badminton and table tennis were taken into the study.

Interviewer administered, pre-tested and validated questionnaires were used. Certain items of information were elicited by direct questioning and some straight observations were made by getting the child to perform certain manoeuvres. Each player was assessed by two of the investigators. The first investigator recorded the demographic data, duration of participation in the sport and the hand used for eating, writing and brushing teeth together with details of injuries sustained during the previous 12 months. The second investigator who was "blinded" to the earlier data then recorded the observed preference for the hand and foot in certain manoeuvres. The laterality of these actions recorded were throwing a ball, threading a needle, arm folding, leg crossing and kicking a ball. The items of data for each student were then merged into a purpose designed computer database in EPI INFO version $6.0 \mathrm{~b}$ and analysed using the facilities of the same programme.

Total number studied was 822 . The males consisted of $54 \%$ of the sample and females accounted for $46 \%$. Majority (91\%) were Sinhalese while $7 \%$ were Muslims and 2\% were Tamils.

At the outset a regression analysis was carried out to determine the correlation of the various observations in determining handedness. The results of the more important assessments are given in Table 6 . 
Table 6

Correlation of the hand used in combinations of different activities

\begin{tabular}{|l|c|}
\hline \multicolumn{1}{|c|}{$\begin{array}{c}\text { Use of the left hand in specified } \\
\text { tasks }\end{array}$} & Correlation coefficient (r) \\
\hline Writing and throwing & $\mathbf{0 . 8 2}$ \\
\hline Writing and brushing the teeth & 0.91 \\
\hline Throwing and brushing the teeth & 0.84 \\
\hline Writing and threading a needle & 0.79 \\
\hline Eating and writing & 0.54 \\
\hline Eating and brushing & 0.56 \\
\hline Eating and throwing & 0.47 \\
\hline
\end{tabular}

Initially, handedness was evaluated using the hand that was utilised to write and throw a ball as these two criteria showed the best correlation in our previous study ${ }^{16}$ and they showed a significantly high correlation $(\mathrm{r}=0.82)$ even in the present study. The results are shown below in Table 7 .

Table 7

Handedness as determined by different activities singly and in combination

\begin{tabular}{|l|c|c|c|}
\hline & $\begin{array}{c}\text { Writing } \\
(\mathbf{\%})\end{array}$ & $\begin{array}{c}\text { Throwing } \\
(\mathbf{\%})\end{array}$ & $\begin{array}{c}\text { Writing \& throwing } \\
(\mathbf{\%})\end{array}$ \\
\hline Left handed & 84 & 81 & $\mathbf{6 9}$ \\
& $(10.2)$ & $(9.9)$ & $\mathbf{( 8 . 2 )}$ \\
\hline Non-left handed & 738 & 741 & 730 \\
& $(89.8)$ & $(90.1)$ & $(88.8)$ \\
\hline
\end{tabular}

The correlation coefficient for the combination of the hand used for writing and holding a toothbrush was found to be significantly high at 0.91 . We then looked at the incidence of left handedness when writing and brushing the teeth were taken together. The results of this evaluation are given below in Table 8 .

Table 8

Handedness as determined by the hand used for writing and brushing teeth

\begin{tabular}{|l|c|c|c|}
\hline & $\begin{array}{c}\text { Writing } \\
(\mathbf{\%})\end{array}$ & $\begin{array}{c}\text { Brushing } \\
(\mathbf{\%})\end{array}$ & $\begin{array}{c}\text { Writing \& brushing } \\
(\mathbf{\%})\end{array}$ \\
\hline Left handed & 84 & 75 & $\mathbf{7 3}$ \\
& $(10.2)$ & $(9.1)$ & $\mathbf{( 8 . 9 )}$ \\
\hline Non-left handed & 738 & 747 & 749 \\
& $(89.8)$ & $(90.9)$ & $\mathbf{( 9 1 . 1 )}$ \\
\hline
\end{tabular}

It was apparent that these results are not all that different to the findings depicted in Table 7.

It was decided to initially use those who wrote with the left hand and threw a ball with the left hand to designate left handedness, just like in our previous study. The current figure of $8.2 \%$ left handers compares favourably with the rate of $7.4 \%$ in the earlier study using the same criteria ${ }^{16}$.

The next step was to look at the incidence of injuries and handedness. We first looked at all the injuries in general and the results of a broad analysis of injuries in left and right handers is given below in Table 9. 
Table 9

Broad analysis of injuries and handedness

\begin{tabular}{|l|l|l|c|}
\hline & Left handers (\%) & Non-left handers (\%) & p \\
\hline Soft tissue injuries & $43 / 69(62 \%)$ & $279 / 730(38 \%)$ & $<0.001$ \\
\hline Muscle injuries & $38 / 69(55 \%)$ & $313 / 730(43 \%)$ & Not significant \\
\hline Joint injuries & $06 / 69(09 \%)$ & $61 / 730(08 \%)$ & Not significant \\
\hline Fractures & $0(0 \%)$ & $29 / 730(04 \%)$ & Not significant \\
\hline
\end{tabular}

It was found that the left handers were significantly more prone to develop soft tissue injuries. There was no significant association of muscle injuries, joint injuries and fractures with left handedness. Although some studies in the world literature have suggested that left handers were more vulnerable to all these injuries ${ }^{18}$, our results did not corroborate this increased susceptibility to all these injuries.

At this stage we proceeded to look at the second objective of this study. It was to see whether there was any relationship between laterality and the side of the body that was predominantly affected by sports injuries.
It was felt that this was an important part of the study as there had been numerous instances of elite sports personnel being "grounded" by injuries. This was also an aspect that had not been addressed by any of the studies in the literature.

The correlation coefficients suggested good correlation of the hand used to write and throw a ball to denote handedness. We then analysed the occurrence of injuries and the side of the injuries using the criteria of the hand used for writing and throwing a ball to denote left handedness. The results are given in Figure 1.

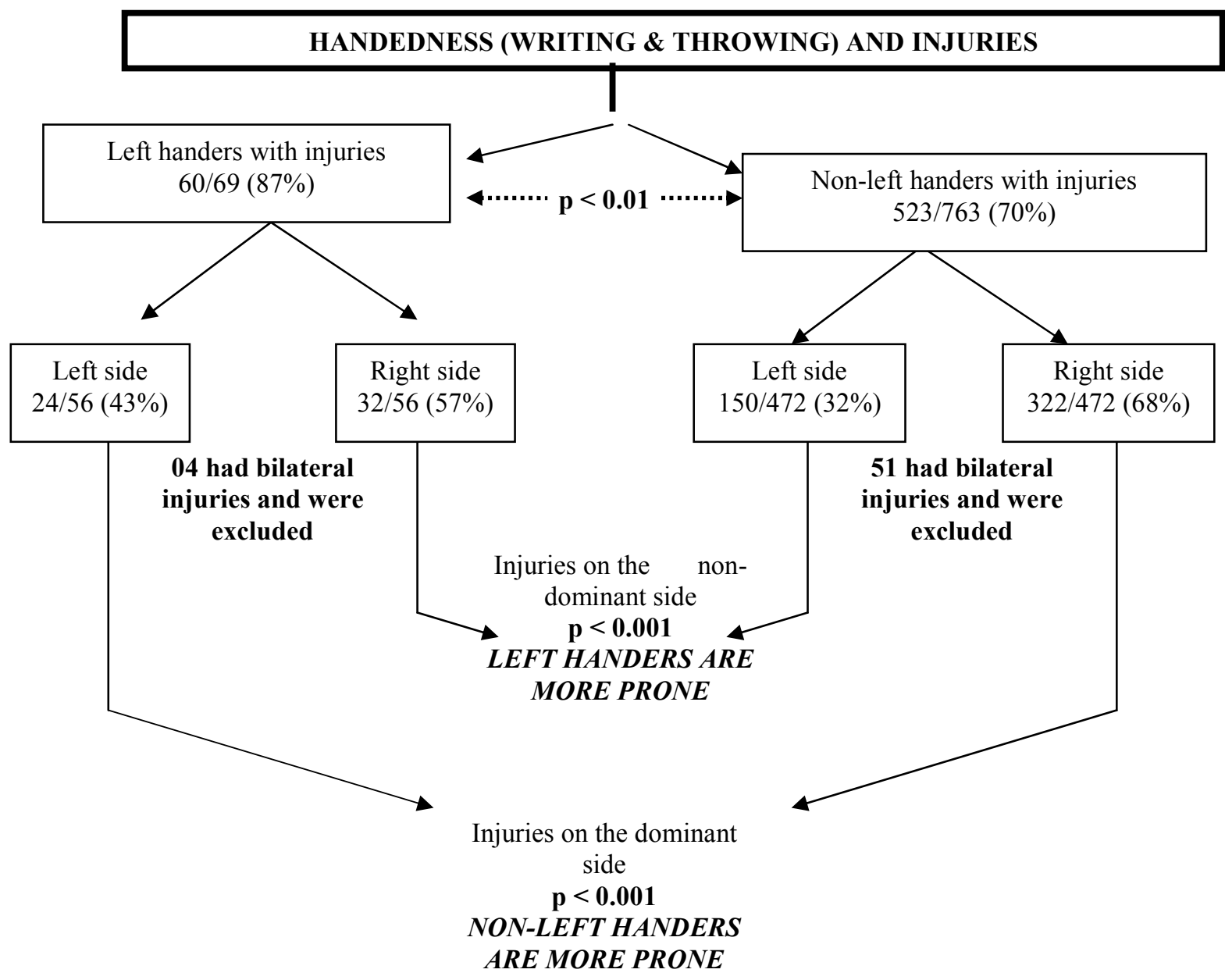

Figure 1 Assessment of handedness utilising hand used for writing and throwing together and incidence of injuries 
The left handers were found to be more prone than non-left handers to develop sports injuries. The left handers were also significantly more prone to develop injuries on the non-dominant side while nonleft handers were significantly more liable to develop injuries on the dominant side. In other words, in both groups, there was a higher incidence of injuries on the right half of the body. This was a curious finding and it prompted us to think of ways of trying to explain these differences.
As the correlation coefficients in Table 6 suggested that the hand used for writing and holding a toothbrush to brush the teeth showed a higher correlation, we proceeded to do the same analysis using those criteria. We looked at the side of the injuries using the hand used for writing and to hold a toothbrush to denote handedness. The results are given in Figure 2.



Figure 2 Assessment of handedness utilising the hand used for writing and brushing together and the incidence of injuries

These results are very similar to the earlier assessment in that the left handers were more liable to develop injuries on the non-dominant side and the non-left handers were more prone to have dominant side injuries.
At this stage we wondered whether the type of sport could be a confounding factor. It is well known that sports injuries are commoner with body contact sports. The next step was to divide the cohort according to whether they were primarily involved in 
body contact sports such as football, rugby, hockey and netball or whether they chiefly took part in nonbody contact sports such as cricket, table tennis, volleyball and badminton. There was some overlap of numbers as some children were in the teams of more than one sport. However, we took pains to select the sport that the child was primarily involved in.
The same analysis of the occurrence of injuries utilising the hand used to write and throw to denote handedness was performed on children taking part in body contact sports. The results are presented in Figure 3.

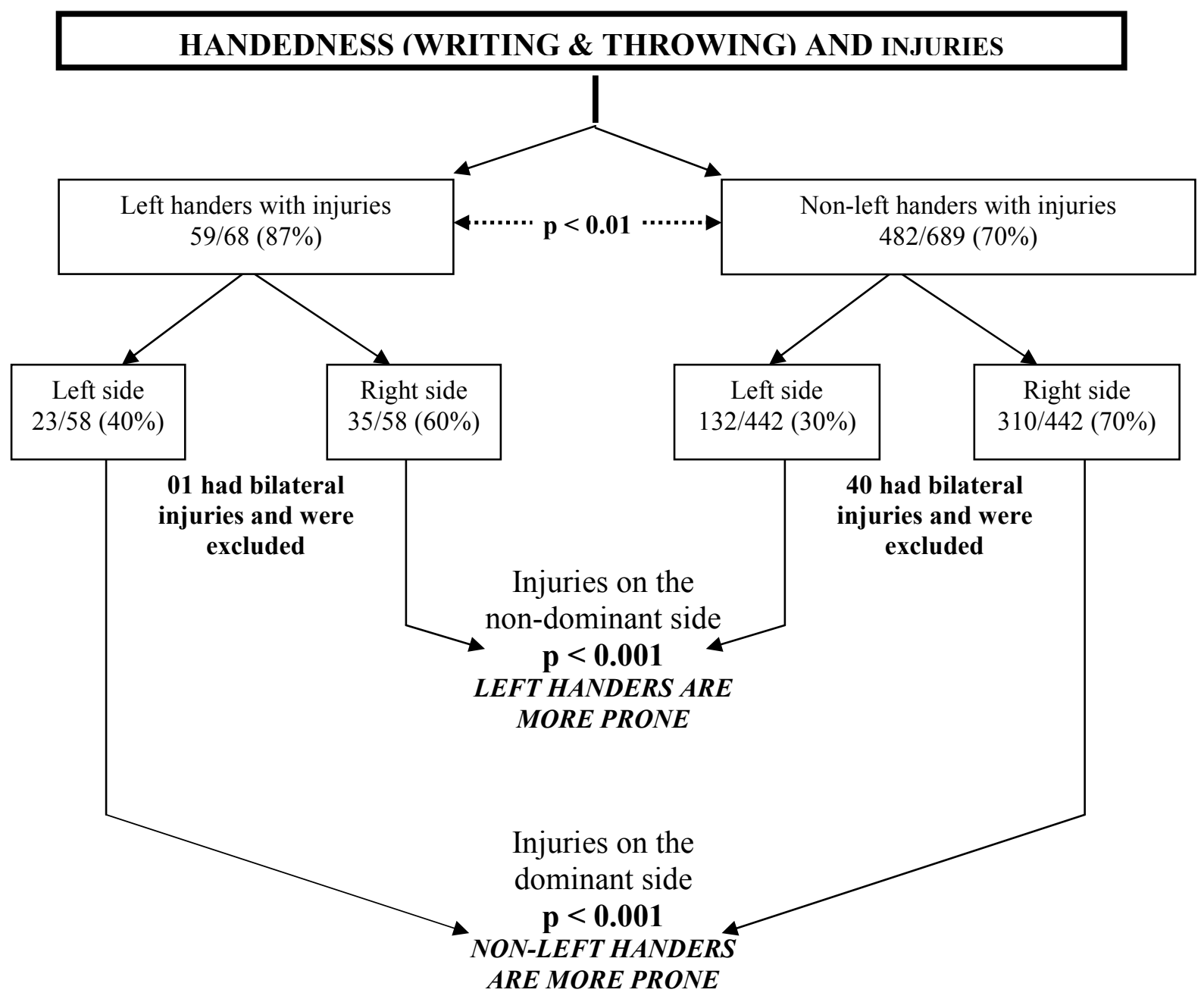

Figure 3 Assessment of handedness utilising the hand used for writing and throwing together and the incidence of injuries in body contact sports (Football, Rugby, Hockey and Netball)

The results were identical to those of the entire cohort. The propensity of left handers to develop injuries and the specific sides of the injuries were the same as in the earlier analysis. The 'p' values in the analysis of the different parameters were very similar. The details of the same assessments performed in non-body contact sports are given in Figure 4. 


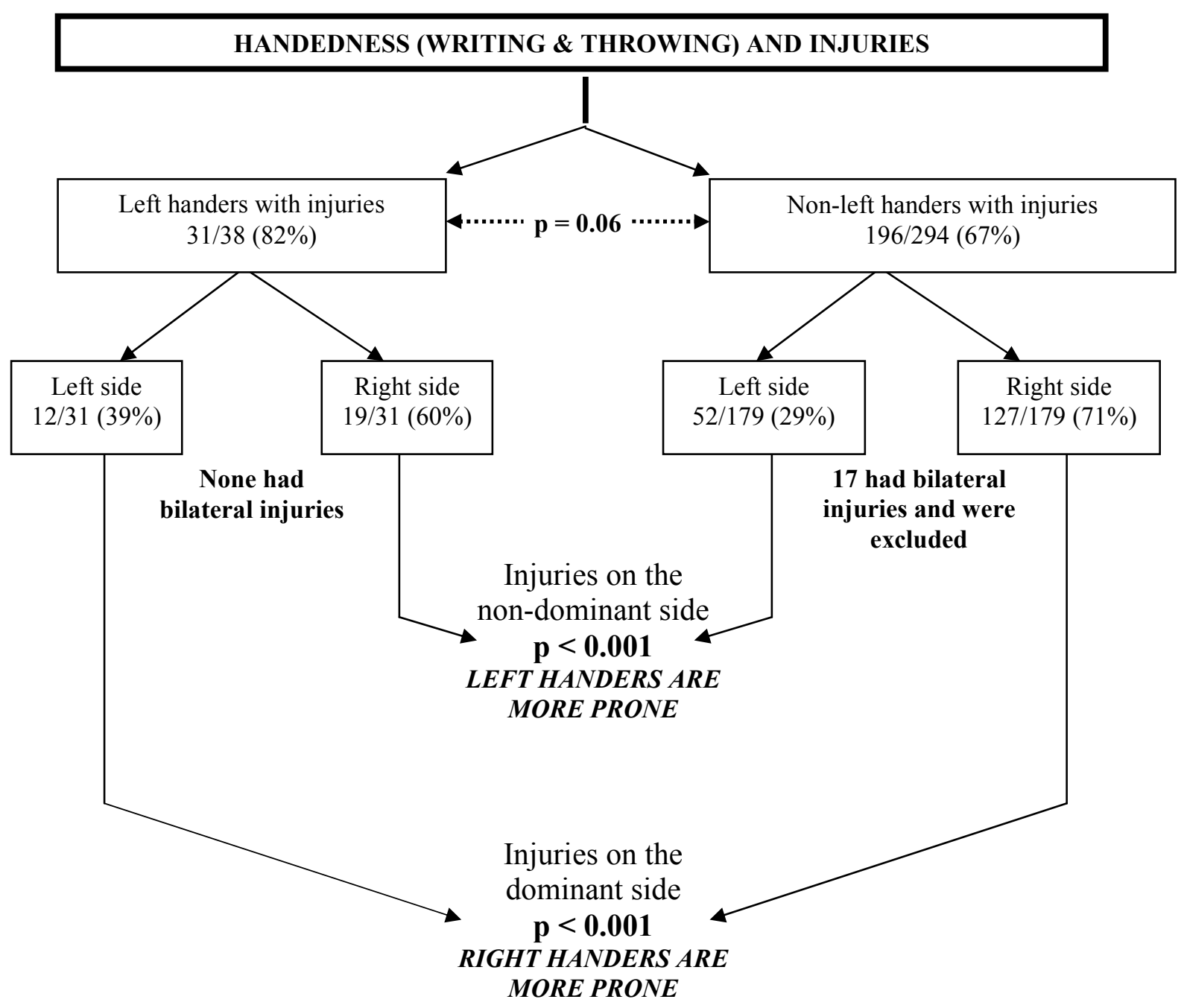

Figure 4 Assessment of handedness utilising the hand used for writing and throwing together and the incidence of injuries in non-body contact sports (Cricket, Table tennis, Volleyball and Badminton)

The results in this analysis differ slightly from the earlier evaluations. The left handers were not significantly more prone to have injuries on the whole $(\mathrm{p}=0.06)$. However, the side of the injuries provided the same results as the earlier two evaluations. The left handers were more prone to develop injuries on the non-dominant side while the non-left handers were liable to develop injuries on the dominant side.

It was our original intention to look at the occurrence of injuries in footedness as well. Many sports rely on mobility as a principal component of the sport itself and it is thought that footedness may have some implications for injuries. We looked at the injury patterns in those who were left footed and those who were non-left footed. Those who predominantly kicked a ball with the left foot were denoted to be left footers. In the entire cohort, $77(9 \%)$ used the left foot for kicking a ball. An analysis similar to those done earlier on handedness and injuries was performed using footedness as the criterion for selection. The results of this analysis are given in Figure 5. 


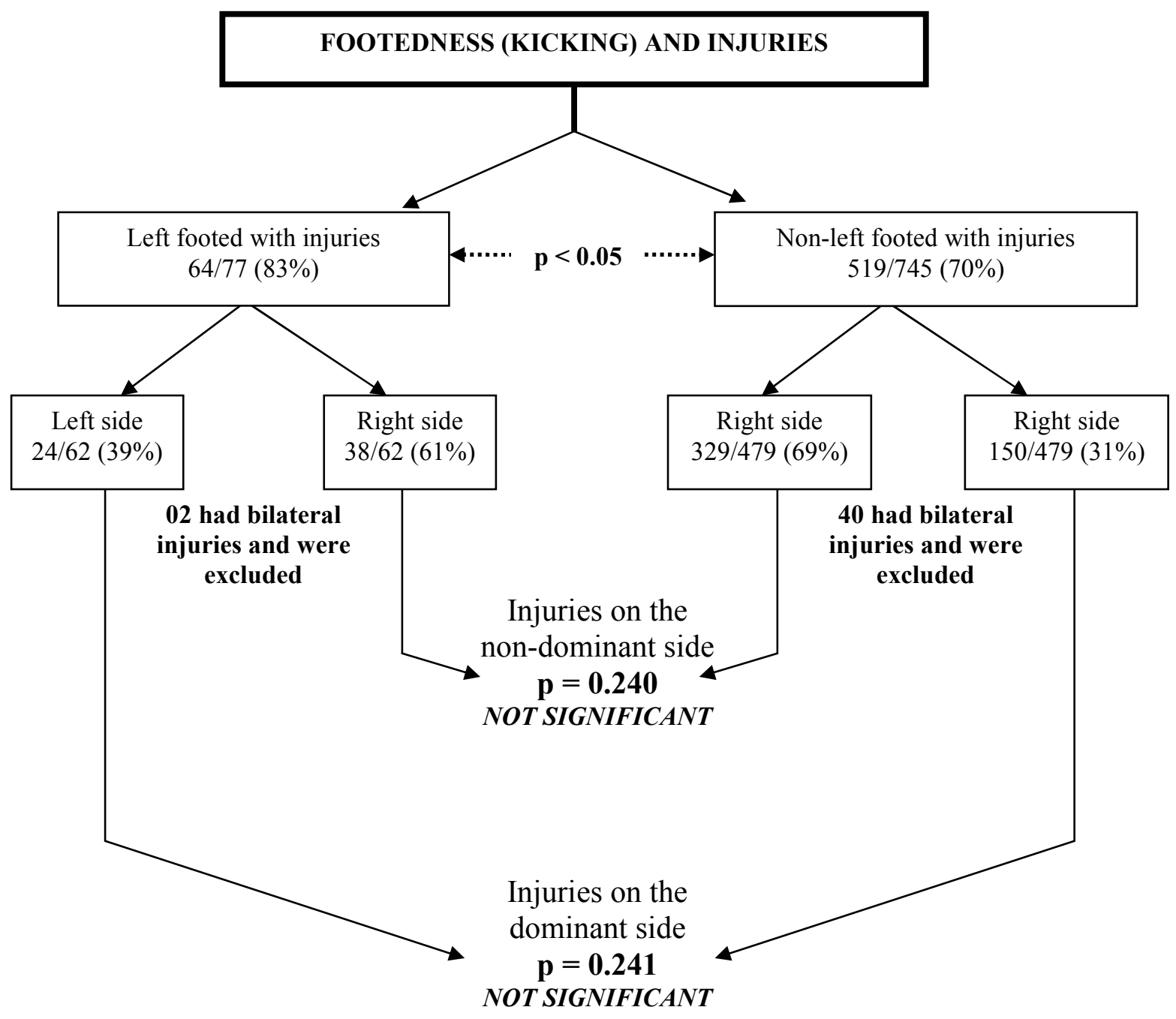

Figure 5 Assessment of footedness utilising the leg used for kicking and the incidence of injuries

The results of this evaluation were quite different. Although those who were left footed were found to be more liable to develop injuries $(\mathrm{p}<0.05)$, there were no statistically significant differences in the side of the injury when those who were left footed were compared to those who were non-left footed. This was a little bit surprising and we tried to find a way of explaining these findings.

Several studies from all over the globe have documented that left handers were more prone to develop unintentional, accidental and sports injuries. The higher incidence of injuries in left handers in the present study is in conformity with the results of the published literature. However, as stated before, there is no information in the literature regarding handedness and susceptibility to injuries on a particular side of the body. An extensive electronic literature search did not come up with even a single study that has looked at this aspect of laterality. In that respect it appears that this is the first study that has looked at this aspect of handedness and footedness.

The present study results show that left handed children taking part in sports are more prone to develop injuries on the non-dominant side while nonleft handed children are more susceptible to the development of injuries on the dominant side. In simplified terms this means that all children and adolescents taking part in competitive sports are more liable to develop injuries over the right side of the body. In the case of left handers, this may be due to the fact that the less strong non-dominant side is 
vulnerable. Yet, this hypothesis does not explain the propensity of non-left handers to develop right sided injuries. It may be postulated that in contact sports such as football, rugby, hockey and netball, the impact is generally on the right side of the body as the majority are right handed and this could explain the non-left handers liability to right sided injuries. It could also explain the predominantly right sided injuries in left handers as they are confronted by nonleft handers virtually $90 \%$ of the time. However, this cannot explain similar occurrences in non-contact sports such as cricket, table tennis, volleyball and badminton.

Left footedness too was significantly associated with an increased incidence of injuries. However, there were no significant differences in the side of the injury and footedness. It is difficult to explain this difference from handedness. Perhaps, one possible mechanism is to suggest that as both lower limbs are used to an equal degree in everyday tasks like walking and running and as a result, there is no significant difference in the strength between them. While there is a preference of a particular foot for kicking, the equal strengths of the two limbs possibly negate any propensity to develop injuries of a particular side.

It has been postulated that the left-top position in arm folding and hand clasping were signs of "latent lefthandedness". Further research has revealed that consistent left top positions are canonical for European right handers and combined measures may provide more information regarding cerebral laterality ${ }^{27}$. Surprisingly enough combined arm folding and hand clasping with left top positions in both seemed to denote right handedness and left hemispheric dominance ${ }^{27}$. The data from studies support Luria's proposition of "latent lefthandedness" when the left top position in arm folding is combined with right top position in hand clasping. This would be a confounding factor in analysis of a series in which one was trying to specifically look for left-handers. The findings of arm folding and hand clasping, though recorded in our series, were not used in the analysis primarily for this reason and also for the second detail that their evaluation in one of our own previous studies had yielded inconsistent findings ${ }^{17}$.

One possible drawback of this particular study is the reliance placed on recall of injuries by children over the last 12 months. Adequate medical records were not available for corroboration of the information provided. This is a factor that may have influenced the results but the consistent findings on several different parameters make this unlikely. However, it must also be pointed out that in many of the studies on laterality and injuries in the world literature, a similar method of recall from memory has been used $^{2,5,6,10}$. Be that as it may, the results of the present study would best be confirmed using proper medical records in a prospective study. If these findings are established, it may provide some insight into possible preventive strategies that could usefully be employed to avert sports injuries.

This study was presented at the $12^{\text {th }}$ Asia Pacific Congress of Paediatrics held in conjunction with the $10^{\text {th }}$ Annual Congress of The Sri Lanka College of Paediatricians in Colombo, Sri Lanka during March $2007^{28}$.

Finally, Ladies and Gentlemen, you might justifiably wonder why I have taken so much trouble to look at laterality. After all, it is well known that my prime interest has been in Childhood Respiratory Disease. The real reason is something quite personal. My own cerebral dominance has baffled me for a very long time and I am sure that it would be quite a puzzle for anyone when you see what I have to offer by way of my own laterality. I write, draw and throw with the right hand. I use the right hand for holding a tooth brush and for using a spoon. When I use a broom, the upper hand is the right hand. I kick habitually with the right foot and punch right fisted. All these suggest right sided body dominance and right handed preference. However, in other instances, I use the left hand. Thus in cricket I bat left handed but bowl right handed. If I have to catch a ball with one hand, I would routinely use the right hand. In all racquet sports like tennis, table tennis and squash, I use the left hand. I use a hammer, knife or a scissor exclusively with the left hand. I strike a match left handed and in opening a box or a lid, I use the left hand. In opening doors, pointing and reaching, I would use the left hand. I would paint a wall left handed. In the Edinburgh Handedness Inventory, I come out marginally left-handed. In arm folding and hand clasping my profile shows up as consistent left side on top indicating right-handedness. In leg crossing, I come out left footed. The only conclusion that could be arrived at using all these criteria is either that I have a totally confused brain or I fall on to that rare ambidextrous category where there is no real dominance of either cerebral hemisphere. For obvious reasons, I would like to plump for the latter option. Yet, if I could go back to the postulations of one of my most revered teachers, Dr. George Ratnavale, I am able to do some things better with the left hand and thus I must be a born left hander. 
In conclusion, Ladies and Gentlemen, the concepts of laterality and handedness have been extremely interesting and quaint features of the human race from time immemorial. Over centuries of time, the homo sapiens have had a love-hate relationship with laterality. At times left-handers have been ridiculed and despised while at other times they have been marvelled at and portrayed as absolutely brilliant. This is a sort of right-handed world and many lefties have had problems in numerous different aspects of day-to-day living. The right-handers have generally been patronizing and have been looking down on the minority lefties in many different fields. Yet for all that, some others have recognised several south-paws as being extremely gifted. These differences, opinions and many versions of different tales are likely to remain with us for as long as the human race survives in this world. What I have done in this presentation is to introduce you to just a few of the many intricacies of laterality. I hope and pray that my efforts have not been in vain in arousing the curiosity of this august audience.

\section{References}

1. Available from http://cwx.prenhall.com/bookbind/pubbooks/mor ris2/chapter2/medialib/lecture/ness.html

2. Sackheim HA, Gur RC, Saucy MC. Emotions are expressed more intensely on the left side of the face. Science 1978; 202:434-6

3. Available from http://cancerweb.ncl.ac.uk/cgi-bin/omd?laterality

4. Available from http://www.netscape.com/tag/left+or+right+hand $\underline{\text { edness }}$

5. Available from http://en.wikipedia.org/wiki/Laterality

6. Szaflarski JP, Binder JR, Possing ET, McKiernan KA, Ward BD, Hammeke TA. Language lateralization in left-handed and ambidextrous people. Neurology 2002; 59:23844

7. Hardyck C, Petrinovich LF. Left-handedness. Psychological Bulletin 1977; 84:385-404

8. Available from http://en.wikipedia.org/wiki/Handedness
9. Salvesen KA, Vatten LJ, Eik-Nes SH, Hugdahl $\mathrm{K}$, Bakketeig LS. Routine ultrasonography in utero and subsequent handedness and neurological development. British Medical Journal 1993; 307:159-64

10. Available from http://www.bbc.co.uk/nature/animals/features/34 1 feature1.shtml

11. Available from http://www.nature.com/mp/journal/vaop/ncurrent /abs/4002053a.html

12. Geschwind N, Behan P. Left-Handedness : Association with Immune Disease, Migraine and Developmental Learning Disorder. Proceedings of The National Academy of Sciences of The United States of America. 1982; 79 (16):5097100

13. Coren S, Halpern S. Left-handedness:a marker for decreased survival fitness. Psychological Bulletin 1993;114 (2):235-47

14. Hicks RA, Beveridge R. Handedness and intelligence. Cortex 1978; 14 (2):304-7

15. Smith J. Left-handedness: its association with allergic disease. Neuropsychologia 1987;25 (4):665-74

16. Wood LC, Cooper DS. Autoimmune thyroid disease, left-handedness and developmental dyslexia. Psychoneuroendocrinology 1992; 17 (1):95-9

17. Perera BJC, Mudalige NA, Lenora RRS, Malintha SDSN, Mendis GLEC, Munasinghe AP, Munasinghe RD, Munasinghe PC. Handedness in schoolchildren. Proceedings of the Sri Lanka College of Paediatricians Annual Scientific Congress 1998; 1(no.2):41-2

18. Perera BJC, Handedness among elite tennis players in Colombo. Proceedings of the Sri Lanka College of Paediatricians Annual Scientific Congress 2000; 2 (no.1):41-2

19. Coren S. Handedness as a Predictor of Increased Risk of Knee, Elbow, or Shoulder Injury, Fractures and Broken Bones. Laterality : Asymmetries of Body, Brain and Cognition 1996; 1(2):139-52 
20. Zverev Y, Adelove A. Left-handedness as a risk factor for head injuries. East African Medical Journal 2001; 78 (1) :22-4

21. Skalkidou A, Petridou E, Dessypris N, Karanikas E, Pistevos G, Trichopoulos D. Risk of upper limb injury in left handed children : a study in Greece. Injury Prevention 1999; 5 (1):68-71

22. Luetters CM, Kelsey JL, Keegan TH, Quesenberry CP, Sidney S. Left-handedness as a risk factor for fractures. Osteoporosis International 2003; 14 (11):18-22

23. Graham CJ, Cleveland E. Left-handedness as an injury risk factor in adolescents. Journal of Adolescent.Health 1995; 16 (1):50-2

24. Wright P, Williams J, Currie C, Beattie T. Lefthandedness increases injury risk in adolescent girls. Perceptual and Motor Skills 1996; 82 (3 Pt 1): $855-8$
25. Dane S, Can S, Karson O. Sports injuries in right- and left-handers. Perceptual and Motor Skills 1999; 89 (3 Pt 1): 846-8

26. Williams JM, Wright P, Currie CF, Beattie TF. Sports related injuries in Scottish adolescents aged 11-15. British Journal of Sports Medicine. 1998; 32 (4): 291-6

27. Mohr C, Thut G, Landis T, Brugger P. Arm folding, hand clasping, and Luria's concept of "Latent left-handedness". Laterality 2006; 11 (1):15-32

28. De Silva ANK, Perera GLKA, Gunasekera TMR, Soodin BAN, Kasthuriarachchi SK, Perera BJC. Relationship between laterality and sports injuries in children and adolescents involved in competitive sports. Proceedings of The $12^{\text {th }}$ Asia Pacific Congress of Paediatrics and $2^{\text {nd }}$ Asia Pacific Congress of Paediatric Nursing 2007; 1 (1): 74-5 